\title{
Early use of magnetic endoscopic imaging by novice colonoscopists: Improved performance without increase in workload
}

\author{
Sylvain Coderre MD FRCPC 1 , John Anderson BSc FRCP(Edin) MD², Remy Rikers PhD ${ }^{3}$, \\ Paul Dunckley MB ChB MRCP DPhil ${ }^{2}$, Karen Holbrook RN² ${ }^{2}$ Kevin McLaughlin MD MRCP4
}

\begin{abstract}
S Coderre, J Anderson, R Rikers, P Dunckley, K Holbrook, K McLaughlin. Early use of magnetic endoscopic imaging by novice colonoscopists: Improved performance without increase in workload. Can J Gastroenterol 2010;24(12):727-732.
\end{abstract}

BACKGROUND: Magnetic endoscopic imaging represents a recent advance in colonoscopy training. This technique provides adjunct information to the endoscopist, specifically with regard to colonoscope loop formation.

OBJECTIVE: To examine the effect of a magnetic endoscopic imager on novice performance and workload in colonoscopy.

METHODS: Twenty complete novices received an introductory teaching session followed by the completion of two procedures on a colonoscopy model. One-half of the participants performed their first procedure with the imager, and the second procedure without, while the other one-half were trained with the inverse sequence. Two main outcome measures were recorded: distance achieved and total workload as measured by the National Aeronautics and Space Administration task load index tool.

RESULTS: A significant improvement was noted between the first and second colonoscopies, with the best performance recorded for participants who performed their first procedure with the imager, and their second without. The imager did not significantly change the total workload.

DISCUSSION: The study participants paid attention to the magnetic endoscopic imager; however, this did not translate into a measurable increase in novice workload. A delayed learning benefit was conferred to the group exposed to the imager on their first colonoscopy, suggesting that, even at an early training stage, the additional imager information entered working memory and was processed in a useful fashion. The introductory teaching strategy used in the present study was successful as judged by the overall distance achieved and performance improvement seen in all study participants.

Key Words: Cognitive load; Endoscopy training; Magnetic endoscopic imaging; Workload

A cquiring competence and subsequent progression toward expertise in the performance of any skill requires a combination of innate biological capability, dedicated teachers, and many hours of training and practice. Skill acquisition has been described as a sequential process involving three major phases (1). The first phase, otherwise known as the novice phase, involves intense concentration to fully understand the activity and to avoid making mistakes. The second phase is more fluid and successful, while less mentally demanding. The final phase

\section{L'utilisation rapide de l'imagerie par endoscopie magnétique par des coloscopistes novices : Un meilleur rendement sans augmentation de la charge de travail}

\begin{abstract}
HISTORIQUE : L'imagerie par endoscopie magnétique est une récente avancée de la formation en coloscopie. Cette technique fournit de l'information supplémentaire à l'endoscopiste, notamment à l'égard de la formation de boucles par le coloscope.

OBJECTIF : Examiner l'effet de l'imagerie par endoscopie magnétique sur le rendement d'un novice et la charge de travail en coloscopie.

MÉTHODOLOGIE : Vingt novices sans aucune expérience ont reçu une séance d'initiation suivie de l'exécution de deux interventions sur un modèle de coloscopie. La moitié des participants a effectué cette première intervention à l'aide d'une imagerie par endoscopie magnétique et la deuxième, sans imagerie, tandis que l'autre moitié à suivi la séquence inverse. Deux grandes mesures d'issue ont été prises en compte : la distance franchie et la charge de travail totale, mesurées d'après l'indice de charge totale de la National Aeronautics and Space Administration.

RÉSULTATS : Les chercheurs ont constaté une amélioration significative entre la première et la deuxième imagerie, le meilleur rendement étant enregistré chez les participants qui avaient effectué la première intervention avec l'imagerie et la deuxième sans l'imagerie. L'imagerie ne modifiait pas la charge de travail de manière significative.

EXPOSÉ : Les participants à l'étude ont porté attention à l'imagerie par endoscopie magnétique, ce qui ne s'est pas traduit par une augmentation mesurable de la charge de travail des novices. Le groupe exposé à l'imagerie lors de la première coloscopie profitait d'un avantage d'apprentissage différé, ce qui laisse supposer que, même en début de formation, l'information supplémentaire fournie par l'imagerie s'imprimait dans la mémoire de travail et était traitée de manière utile. Cette stratégie d'initiation était réussie, telles que le démontraient la distance franchie et l'amélioration du rendement observée chez la totalité des participants à l'étude.
\end{abstract}

is increasingly automatic, smooth and precise, with little or no conscious mental involvement. This three-step process has also been described by others (2) in terms of cognitive, associative and autonomous phases. Consistent in both these and other models of skills acquisition (3) is that the initial novice phase is particularly demanding on many cognitive processes including attention. Designing an educational intervention at this cognitively vulnerable stage of training requires strict adherence to the principles outlined in cognitive load theory (CLT).

${ }^{1}$ Department of Medicine, Division of Gastroenterology, University of Calgary, Calgary, Alberta; ${ }^{2}$ Department of Gastroenterology,

Gloucestershire Hospitals NHS Foundation Trust Hospital, United Kingdom; ${ }^{3}$ Faculty of Social Sciences, Erasmus University Rotterdam,

Rotterdam, The Netherlands; ${ }^{4}$ Office of Undergraduate Medical Education, University of Calgary, Calgary, Alberta

Correspondence: Dr Sylvain Coderre, Department of Medicine, Division of Gastroenterology, University of Calgary, 3500-26th Avenue

Northeast, Calgary, Alberta T1Y 6J4. Telephone 403-943-5708, fax 403-943-4471, e-mail scoderre@shaw.ca

Received for publication June 21, 2010. Accepted June 26, 2010 
CLT focuses on developing effective and efficient instructional strategies to support skill acquisition in educational settings. First described by Sweller (4), CLT fundamentally suggests that "instructional design should explicitly consider the human cognitive architecture and its limitations in order to be effective" $(5,6)$. This cognitive architecture is composed of unlimited long-term memory interacting with a limited working memory. Working memory is limited both in space $(4 \pm 1$ elements if processing information) and time (unrehearsed information lost within $30 \mathrm{~s}$ ) (7). A third memory system - visual and auditory sensory memory - temporarily stores information before moving it to working memory (8). The process of storage in sensory memory and subsequent transfer to working memory relies on focused attention directed toward the stimulus (9).

In general, three types of cognitive load have been presented in CLT. The first, intrinsic load, is caused by the complexity of the task itself (7). Intrinsic load is modifiable and reducible (10). The second, extraneous cognitive load, is harmful to learning and can be altered by instructional interventions (11). The third is germane cognitive load, a desirable load that is beneficial for learning. An ideal educational intervention reduces task complexity (intrinsic load) and eliminates extraneous cognitive load, thus freeing all cognitive resources to generate germane load and promote genuine learning (12).

Endoscopy of the entire colon, known as colonoscopy, was first described in 1971. Today, colonoscopy is a common diagnostic and therapeutic procedure performed worldwide (13). A standard colonoscopy requires attention to and processing of several sensory stimuli: visual stimuli from the endoscopic image of the colon on the video monitor, verbal stimuli from patient, nurses and, potentially, a trainer, as well as proprioceptive/tactile stimulus from the colonoscope itself. During a colonoscopy training session, a novice must attend to and process all of these stimuli to proceed successfully and safely.

The majority of difficulties encountered during a colonoscopy result from lack of progression of the instrument after insertion - commonly as a consequence of colonoscope looping within the colon. To progress safely, effectively and with minimal patient discomfort normally requires straightening of the instrument and resolution of the loop (14). Traditionally, information about colonoscope looping was received by way of verbal and/or visual evidence of patient discomfort, and/or proprioceptive stimulus to the endoscopist such as lack of one-to-one advance and paradoxical scope movement (15). Fluoroscopy had been used to aid in scope positioning and advancement. However, a more recent innovation, magnetic endoscopic imaging (ScopeGuide, Olympus, Japan), accomplishes these tasks without use of ionizing radiation. Magnetic endoscopic imaging uses a magnetic field to induce coils in the instrument, which are detected and processed to produce a three-dimensional image of the colonoscope. It has been described as providing accurate and useful adjunct information to the endoscopist, specifically with regard to loop formation $(16,17)$. Studies using the imager in clinical practice have generally yielded favourable results regarding its usefulness in easing colonoscopy completion $(16,18,19-21)$, endoscope and lesion location $(17,22,23)$, patient comfort $(16,17,19,24)$ and rating colonoscopy competence $(25)$. In one study (22), no difference was found in colonoscopy performance when using the imager.
The ScopeGuide imager, which is not universally available or used for colonoscopy, is believed to be a useful adjunct to teaching colonoscopy (26). The benefit of the imager in endoscopic training has been shown in more experienced trainees (16) and in the longitudinal follow-up of a single, less experienced trainee (27). The usefulness of the additional visual information provided by the ScopeGuide imager in subjects beginning endoscopic training has not been studied directly. An additional piece of information regarding colonoscope position and looping in the colon should be a positive adjunct to endoscopy training; however, the potential remains for this additional visual stimulus to increase extraneous cognitive load and, thus, overwhelm mental resources. This is particularly true in light of evidence in the sports medicine literature (28) suggesting that visual information can dominate resources when competing with verbal and tactile inputs.

The main research question in the present investigation concerned the presentation of the additional visual stimulus provided by the ScopeGuide imager to novice endoscopists. The additional information provided by the imager regarding endoscope tip position could provide a source of germane cognitive load by generating a genuine understanding of this fundamental endoscopic concept, thus resulting in improved performance. However, we hypothesized that this potentially useful adjunct presented at the onset of training would increase extraneous cognitive load. An increase in this harmful cognitive load at such a vulnerable stage of training, in which cognitive resources are already heavily taxed by other stimuli, would ultimately result in poorer performance.

\section{METHODS}

Ethics approval for the present study was granted by the National Research Ethics Service in the United Kingdom. A total of 20 volunteer participants with a variety of backgrounds were recruited from the law and business sectors, and also included medical secretaries and university students. Only one participant had previous formal training in a medicine-related field (retired physiotherapist in the 'ImagerFirst' group). The participants were recruited on a voluntary basis, with no promise of remuneration for participation.

Informed consent was obtained from the participants on their arrival. The study was performed using two participants per session. For each pairing, the participants were randomly assigned to one of two groups by draw from a hat.

The total study time for each participant was $1 \mathrm{~h}$. In the first $30 \mathrm{~min}$, an experienced endoscopist and trainer demonstrated a hands-on introduction to colonoscopy. This session included a general introduction to the colonoscope and its handling, a description and interpretation of the video image on the monitor as well as allowing the participants to handle the instrument to instruct on basic manoeuvres used in steering (wheels and torque). Following the introduction, the study participants were given 4 min to perform a relatively straightforward technical skill, both from a cognitive and motor perspective. The participants were asked to navigate the colonoscope into a standard shoe box and subsequently asked to deflect the tip of the colonoscope to the right through a hole cut out from the right side of the box, followed by a similar manoeuvre using a hole on the left side of the box. They were then asked to deflect the tip of the colonoscope up to identify various 
drawings made on the internal and superior aspect of the box. This exercise was selected because it was relevant to the pending task and offered some cognitive and physical demand, yet not at the level of a diagnostic colonoscopy. After performing the exercise, the participants were asked to complete the workload assessment presented below to eliminate any confusion regarding the actual workload instrument. The overall aim of this 30 min session was to construct a whole-task teaching methodology beginning with a very simple task class (11).

The following $30 \mathrm{~min}$ were supervised by a certified gastroenterologist and experienced colonoscopy trainer. The basic concept of colonoscope looping was explained to the participants, who were also shown the additional visual information on scope position provided by the Olympus ScopeGuide. Following this 5 min presentation, the participants performed two time-limited (10 $\mathrm{min}$ ) colonoscopies on identical colonoscopy models. One of the groups performed their first colonoscopy with use of the Olympus ScopeGuide, and their second without the visual guide. This group was referred to as the 'ImagerFirst' group. The second group performed their first colonoscopy without use of the Olympus ScopeGuide, and their second with the visual guide. This group was referred to as the 'ImagerSecond' group. The trainer provided unprompted, brief, direct verbal advice to the participants in both groups, beginning $90 \mathrm{~s}$ into the endoscopy and then at regular $90 \mathrm{~s}$ intervals throughout the procedure unless specifically asked for help by the participant.

Three outcome measures were recorded. The first was the distance (in $\mathrm{cm}$ ) reached by the study participant during each colonoscopy. The colonoscopy models that were used allowed for accurate distance assessment because they could be opened at the end of the procedure and an exact measurement of scope position could be made. The second outcome measure was an assessment of workload. After each colonoscopy, the participants were asked to complete a brief questionnaire subjectively rating various aspects of workload (no more than 2 min to complete). Measuring mental effort during deliberate practice and relating these measures to the level of performance provides a good estimate of the efficiency of the ongoing processes (29). Subjective ratings are generally valid, sensitive and practical indicators of mental workload (30). The workload assessment is an adaptation of the National Aeronautics and Space Administration task load index. This tool has been extensively validated, with its use reported in more than 500 publications since its development (31). It has also has been used in the field of medicine (32).

An adaptation of the tool is presented in Figure 1. For each of the six items, participants place an ' $x$ ' on a line $12 \mathrm{~cm}$ in length, which is subsequently converted to a numerical value for each of the items. In addition, assessment of total workload can be completed by simply summing the scores of the six subscales.

Although a $10 \mathrm{~min}$ time limit was placed on participants to complete the task, a measure of progression rate was believed to be important. Considering this aim, a third outcome measure, time required to reach maximal distance, was recorded.

Paired $t$ tests were used to compare the use of the imager (or not) and the order in which the colonoscopies with the imager were performed (first or second) for the three outcome measures, while independent $t$ tests were used to compare the four study conditions (two groups in their two colonoscopies) for the three outcome measures.

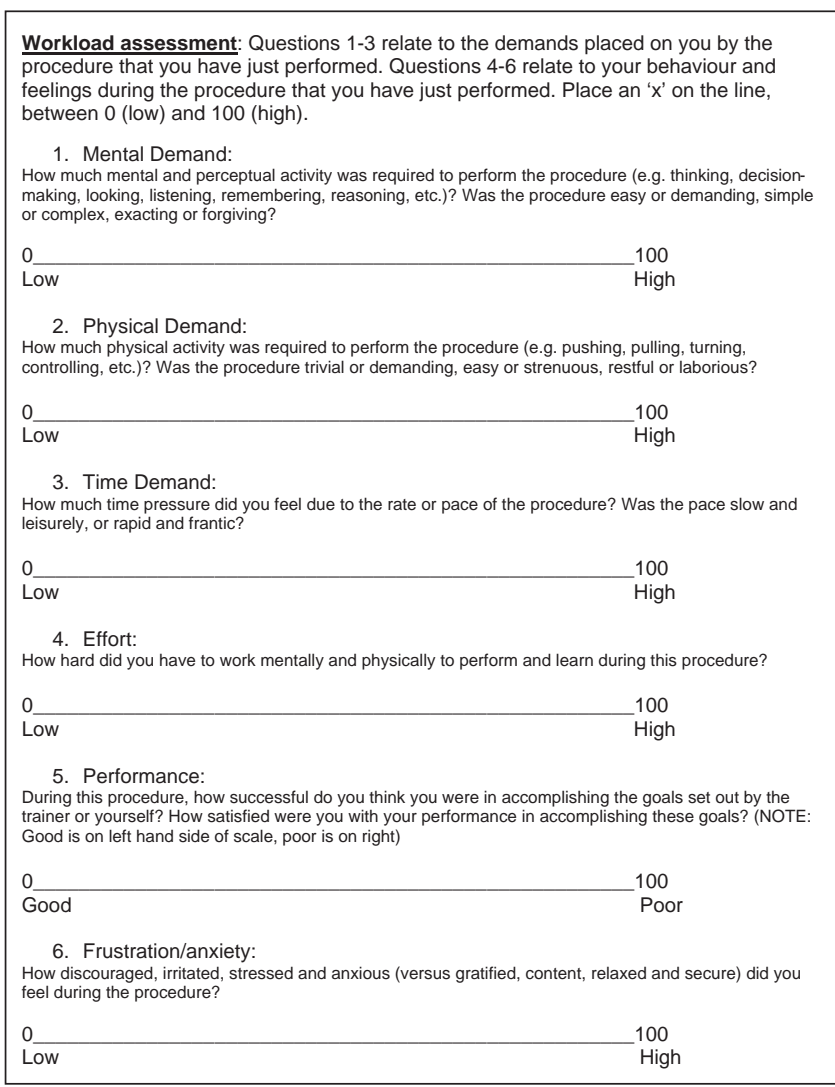

Figure 1) Workload questionnaire. Adapted from the National Aeronautics and Space Administration task load index (32)

Given the small sample size, an a priori decision was made to eliminate extreme performance outliers from the analysis. One participant in the ImagerSecond group was eliminated from the analysis due to their distance matching that of an experienced colonoscopist on the same model. A sensitivity analysis was performed and confirmed the appropriateness of this decision.

\section{RESULTS}

The man to woman ratio and age distribution of both groups were similar.

Table 1 summarizes the comparison of procedures performed by both groups with and without the imager. There were no significant differences associated with mean distance and total workload between the groups. This analysis intentionally removed the importance of the order in which the colonoscopies were performed. In both groups with/without imager, onehalf of the procedures were the participants' first scope, and one-half their second.

Table 2 compares the first and second procedures performed by both groups. A significant improvement occurred in the mean distance achieved between the first and second colonoscopies. This analysis intentionally removed the confounding potential of the imager because, in both groups, one-half of the procedures were performed with the imager and one-half without.

Table 3 compares the distance achieved by the ImagerFirst group on their second procedure and that of the ImagerSecond group on their second procedure. The results represent an independent $t$ test investigating differences between the two groups regarding distance achieved and total workload. 
TABLE 1

Distance and total workload with and without imager

\begin{tabular}{|c|c|c|c|}
\hline & \multicolumn{2}{|c|}{$\begin{array}{c}\text { ImagerFirst and ImagerSecond } \\
\text { groups' scopes }\end{array}$} & \multirow[b]{2}{*}{$\mathrm{P}^{*}$} \\
\hline & $\begin{array}{l}\text { With imager } \\
\quad(n=19)\end{array}$ & $\begin{array}{l}\text { Without imager } \\
\quad(n=19)\end{array}$ & \\
\hline Mean distance, $\mathrm{cm}$ & 32.4 & 34.0 & 0.639 (NS) \\
\hline Total workload $^{\dagger}$ & 398.4 & 377.5 & 0.332 (NS) \\
\hline
\end{tabular}

*Paired $\mathrm{t}$ test; ${ }^{\dagger}$ Total workload measured using the National Aeronautics and Space Administration task load index. NS Not significant

TABLE 2

Distance and total workload: First and second colonoscopies

\begin{tabular}{lccc}
\hline & \multicolumn{2}{c}{$\begin{array}{l}\text { ImagerFirst and ImagerSecond } \\
\text { groups' scopes }\end{array}$} & \\
\cline { 2 - 3 } & First $(\mathbf{n}=\mathbf{1 9})$ & Second $(\mathbf{n}=19)$ & $\mathbf{P}^{*}$ \\
\hline Mean distance, cm & 29.0 & 37.4 & 0.006 \\
Total workload $^{\dagger}$ & 404.5 & 371.4 & 0.116 \\
\hline
\end{tabular}

${ }^{*}$ Paired t test; ${ }^{\dagger}$ Total workload measured using the National Aeronautics and Space Administration task load index

These results suggest a trend for superior performance for the ImagerFirst group over the ImagerSecond group during their second procedure.

The mean distance achieved by the ImagerFirst group during their second colonoscopy $(41.00 \mathrm{~cm})$ was statistically longer than the distance this same group achieved in their first attempt $(31.50 \mathrm{~cm})$, and also significantly longer than the ImagerSecond group's first mean colonoscopy distance $(26.11 \mathrm{~cm})(\mathrm{P}<0.001)$. No difference was found in the distance achieved by both groups during their first attempt at colonoscopy.

No differences with respect to 'time to maximal distance' were found in any of the analyses; therefore, this outcome measure was omitted from the tables.

\section{DISCUSSION}

The present study yielded three major findings. First, contrary to the original hypothesis, there were no detrimental effects to novice endoscopists in performance, workload or mental demand in the early presentation of the magnetic endoscopic imager (ScopeGuide) (Table 1). Second, the significant increase in distance achieved from the first to the second colonoscopy (Table 2) supports the theory that a well-constructed educational intervention, even of limited duration such as in the current study ( $1 \mathrm{~h})$, can lead to an early gain in novice performance. Finally, the results reported in Table 3 raise the possibility of a 'delayed positive' response to the use of the imager because the overall best performing experimental condition was seen in the group that performed their first colonoscopy with the imager and their second without.

We hypothesized that the early presentation of the magnetic endoscopic imager to such novice endoscopists would lead to an increase in cognitive load. This would exceed mental resources and, thus, potentially lead to a measurable decrease in performance associated with an increase in mental demand and total workload. The results reported in Table 1 do not support this hypothesis. One possible explanation for this apparent neutral effect of the imager is that the participants did not use the information provided by the imager. Without attention, stimuli cannot enter sensory memory or be transferred to
TABLE 3

Distance and total workload: ImagerFirst versus ImagerSecond groups for second colonoscopy

\begin{tabular}{lccc}
\hline & $\begin{array}{c}\text { ImagerFirst group, } \\
\text { second colonoscopy } \\
(\mathbf{n = 1 0 )}\end{array}$ & $\begin{array}{c}\text { ImagerSecond group, } \\
\text { second colonoscopy } \\
(\mathbf{n}=\mathbf{9})\end{array}$ & $\mathbf{P}^{*}$ \\
\hline Mean distance, $\mathrm{cm}$ & 41.0 & 33.3 & 0.072 \\
Total workload $^{\dagger}$ & 356.7 & 387.8 & 0.412 \\
\hline
\end{tabular}

${ }^{*}$ Paired t test; ${ }^{\dagger}$ Total workload measured using the National Aeronautics and Space Administration task load index

working memory and, thus, would not factor into the measurement of mental demand and total workload. Even in the face of high cognitive load situations, a recent study (33) reported that central mechanisms can still be engaged to suppress taskrelevant stimuli such as the imager used in our study. However, we believe information provided by the imager was used for several reasons. First, the results reported in Table 3 suggest that the effect of the imager was not completely neutral and, in fact, exerted a positive, albeit delayed, influence. Second, the participants were all formally introduced to the imager before starting their two colonoscopies, and the verbal instruction from the preceptor included references to the colonoscope tip and looping information provided by the imager. Third, the imager monitor was placed in close visual proximity to the traditional monitor image of the model colonic lumen. Finally, feedback obtained from the participants suggested that they paid attention to the additional visual stimulus.

It is probable that the degree of sensory input from the imager was less than that from more critical stimuli such as the view of the colonic lumen, the proprioceptive feedback from the endoscope and the verbal instructions from the consultant gastroenterologist present in the room. Recent evidence from several studies including functional magnetic resonance imaging data (34-37) suggest that attention to visual, spatial and, possibly, verbal sensory stimuli, share a common pathway that 'bottlenecks' at the central level. In the face of competing sensory stimuli more critical to task completion than the magnetic endoscopic imager, the amount of stimulus from the imager 'breaking through' this bottleneck is likely to be small. This would explain the absence of imager impact on measures of mental demand and total workload.

The second study finding was, perhaps, an expected one. There was a performance gain noted between the first and second colonoscopies (Table 2). The overall performance results of the second colonoscopy (mean distance of $37.4 \mathrm{~cm}$ ) would place the tip of the colonocope somewhere in the sigmoid colon. Given that these participants had no previous training whatsoever, we might consider this a successful training session if distance achieved was the primary objective. Feedback regarding the teaching component of the study was rated favourably by the participants. The study design could be reproduced for novice endoscopic trainees in any gastroenterology subspecialty program. The introduction included all of the essential components of basic colonoscope handling and steering, followed by a very simple endoscopic task. This approach used a whole-task rather than a partial-task instructional design, beginning with a simple task (box model) before progressing to a more complex class of task (two colonoscopies). This approach is supported by the literature, particularly 
for complex procedures integrating knowledge, skills and attitude (38). Another important training component of the study was the support and feedback provided to the participants. This was immediate and fully embedded in the learning task and, thus, more likely to be effective (39).

The study found that the ImagerFirst group achieved their best performance in terms of distance achieved with their second colonoscopy (Table 3). This was the most successful experimental condition, significantly outperforming both groups' first colonoscopy, and trending to outperform the ImagerSecond group's second colonoscopy distance. We hypothesize a delayed benefit from the imager as an explanation for these results. As discussed above, we believe that the participant paid some attention to the imager, an amount likely dwarfed by more directly required information such as the image of the colonic lumen and teacher feedback. Not only was the amount of imager information reaching working memory likely to be small, the high cognitive load state associated with the initial colonoscopy made it difficult to process and apply this information. Consistent with the isolated elements hypothesis (10), material presented in isolation (in our case, the imager) can form an early schema, even if it is initially not fully understood. Therefore, the ImagerFirst group could have used the short time interval between the two colonoscopies to access the primitive schema formed during their first case and used the fundamental principles taught by the imager in their second procedure, thus, resulting in improved performance. We hypothesize that, although not physically present during the second colonoscopy, the mental representation and principles taught by the imager were still present.

\section{Implications for medical education}

The results of the present study support a role for the Olympus ScopeGuide in endoscopy training, in addition to its previously demonstrated benefit in performing routine colonoscopy. The guide is a development in technology not currently universally

\section{REFERENCES}

1. Ericcson A. Deliberate practice and the acquisition and maintenance of expert performance in medicine and related domains. Acad Med 2004;79:570-81.

2. Dickinson J, Weeks D, Randall B, Goodman D. One-trial motor learning. In: Williams AM, Hodges NJ, eds. Skill Acquisition in Sport: Research, Theory and Practice. London: Routledge, 2004:63-83.

3. Starkes J, Cullen J, Macmahon C. A life-span model of the acquisition and retention of expert perceptual-motor performance. In: Williams AM, Hodges NJ, eds. Skill Acquisition in Sport: Research, Theory and Practice. London: Routledge, 2004:259-81.

4. Sweller J. Cognitive load during problem solving: Effects on learning. Cognitive Sci 1988;12:257-85.

5. Paas F, Renkl A, Sweller J. Cognitive load theory and instructional design: Recent developments. Educ Psychol 2003;38:1-4.

6. Van Gog T, Ericsson A, Rikers RM, Paas F. Instructional design for advanced learners: Establishing connections between the theoretical frameworks of cognitive load and deliberate practice. ETR\&D 2005;53:73-8.

7. Ayres P, Paas F. Interdisciplinary perspectives inspiring a new generation of cognitive load research. Educ Psychol Rev 2009;21:1-9.

8. Clark R, Harrelson G. Designing instruction that supports cognitive learning processes. J Athl Training 2002;37:S152-59.

9. Khalil M, Paas F, Johnson T, Payer A. Interactive and dynamic visualizations in teaching and learning of anatomy: A cognitive load perspective. Anat Rec B: New Anatomist 2005;286B:15-20. used in colonoscopy training. It appeared that the additional information provided by the imager during training was not detrimental and was likely beneficial even very early in colonoscopy training. The delayed benefit of the imager demonstrated in the current study suggests that the principles of colonoscope looping taught by the imager can be incorporated early in training. Therefore, even if a training unit does not have access to the imager, presentation of its images and basic principles may still be beneficial. Finally, we demonstrated a whole-task training session, starting from a simple task and progressing to a more complex task, which seemed effective in early endoscopic teaching and training.

\section{Limitations and future direction}

The number of participants was small and the study needs to be repeated, not only with more participants, but also allowing the participants a chance at a third endoscopy without the imager. If the hypothesis raised to explain the results reported in Table 3 is correct, then the ImagerSecond group should catch up to the performance of the ImagerFirst group with a third procedure. In addition, a third group performing two procedures without the imager would have helped to more clearly separate the cumulative learning effect from the imager. The present study did not directly measure participant attention to the imager, which, of course, would provide an immediate answer as to whether information from the imager even had a opportunity to enter working memory and alter cognitive load. Due to technical constraints imposed by the room used for the present study, there was no use of the air/water and suction functions normally used in colonoscopy. The latter add another level of proprioceptive stimuli, which may have influenced the results.

ACKNOWLEDGEMENT: The authors thank Gloucestershire Hospitals NHS Foundation Trust (United Kingdom) for providing facilities for this study.
10. Pollock E, Chandler P, Sweller J. Assimilating complex information. Learn Instr 2002;12:61-86.

11. van Merriënboer J, Sweller J. Cognitive load theory and complex learning: Recent developments and future directions. Educ Psychol Rev 2005;17:147-77.

12. van Merriënboer J, Sluijsmans D. Toward a synthesis of cognitive load theory, four-component instructional design, and self-directed learning. Educ Psychol Rev 2009;21:55-66.

13. Thuraisingham A, MacDonald J, Shaw I. Insights into endoscopy training: A qualitative study of learning experience. Med Teac 2006;28:453-9.

14. Shah SG, Saunders BP, Brooker JC, Williams CB. Magnetic imaging of colonoscopy: An audit of looping, accuracy and ancillary maneuvers. Gastrointest Endosc 2000;52:1-8.

15. Anderson J. Teaching colonoscopy. In: Waye JD, Rex DK, Williams CB, eds. Colonoscopy: Principles and Practice, 2nd edn. New York: Wiley-Blackwell, 2009:141-53.

16. Shah SG, Brooker JC, Williams CB, Thapar C, Saunders BP. Effect of magnetic endoscope imaging on colonoscopy performance: A randomised controlled trial. Lancet 2000;356:1718-22.

17. Shah SG, Brooker JC, Thapar C, Suzuki N, Williams CB, Saunders BP. Effect of magnetic endoscope imaging on patient tolerance and sedation requirements during colonoscopy: A randomized controlled trial. Gastrointest Endosc 2002;55:832-7.

18. Ambardar S, Arnell TD, Whelan RL, Nihalani A, Forde KA. A preliminary prospective study of the usefulness of a magnetic 
endoscope locating device during colonoscopy. Surg Endosc 2005;19:897-901.

19. Jess P, Bulut O, Almasi A, Waaddegaard P. The usefulness of a magnetic endoscope locating device in colonoscopy in daily practice: a prospective case-controlled study. Surg Endosc 2009;23:1353-5.

20. Hoff $G$, Bretthauer M, Dahler S, et al. Improvement in caecal intubation rate and pain reduction by using 3-dimensional magnetic imaging for unsedated colonoscopy: A randomized trial of patients referred for colonoscopy. Scand J Gastroenterol 2007;42:885-9.

21. Shah SG, Brooker JC, Williams CB, Thapar C, Suzuki N, Saunders BP. The variable stiffness colonoscope: Assessment of efficacy by magnetic endoscope imaging. Gastrointest Endosc 2002;56:195-201.

22. Cheung HY, Chung CC, Kwok SY, Tsang WW, Li MK. Improvement in colonoscopy performance with adjunctive magnetic endoscope imaging: A randomized controlled trial. Endoscopy 2006;38:214-7.

23. Shah SG, Pearson HJ, Moss S, Kweka E, Jalal PK, Saunders BP. Magnetic endoscope imaging: A new technique for localizing colonic lesions. Endoscopy 2002;34:900-4.

24. Shah SG, Brooker JC, Thapar C, Williams CB, Saunders BP. Patient pain during colonoscopy: An analysis using real-time magnetic endoscope imaging. Endoscopy 2002;34:435-40.

25. Shah SG, Thomas-Gibson S, Brooker JC, et al. Use of video and magnetic endoscope imaging for rating competence at colonoscopy: Validation of a measurement tool. Gastrointest Endosc 2002;56:568-73.

26. Williams C, Thomas-Gibson S. Rational colonoscopy, realistic simulation and accelerated teaching. Gastrointest Endosc Clin N Am 2003;16:457-70.

27. Shah SG, Thomas-Gibson S, Lockett M, et al. Effect of real-time magnetic endoscope imaging on the teaching and acquisition of colonoscopy skills: Results from a single trainee. Endoscopy 2003;35:421-5.
28. Khan M, Franks I. Specificity of practice. In: Williams AM, Hodges NJ, eds. Skill Acquisition in Sport: Research, Theory and Practice. London: Routledge, 2004:45-62.

29. Rikers RM, Van Gerven P, Schmidt HG. Cognitive load theory as a tool for expertise development. Instr Sci 2004;32:173-82.

30. Hart S, Staveland L. Development of NASA-TLX (task load index): Results of empirical and theoretical Research. In: Hancock P, Meshkati N, eds. Human Mental Workload. Amsterdam: North Holland Press, 1988:239-50.

31. Hart S. NASA-task load index (NASA-TLX): 20 years later. $<$ http://humansystems.arc.nasa.gov/groups/TLX/tlxpublications. html $>$ (Accessed on November 17, 2010).

32. Young G, Zavelina L, Hooper V. Assessment of workload using NASA task load index in perianesthesia. J Perianesth Nurs 2008;23:102-10.

33. Rissman J, Gazzaley A, D'Esposito M. The effect of non-visual working memory load on top-down modulation of visual processing. J Neuropsychologia 2009;47:1637-46.

34. Barrouillet P, Bernardin S, Camos V. Time constraints and resource sharing in adults' working memory spans. J Exp Psychol Learn 2004;133:83-100.

35. Barrouillet P, Bernardin S, Portrat S, Vergauwe E, Camos V. Time and cognitive load in working memory. J Exp Psychol Learn 2007;33:570-85.

36. Tomasi D, Chang L, Caparelli E, Ernst T. Different activation patterns for working memory load and visual attention load. Brain Res 2007;1132:158-65.

37. Vergauwe E, Barrouillet P, Camos V. Visual and spatial memory are not that dissociated at all: A time-based resource sharing account. J Exp Psychol Learn 2009;35:1012-28.

38. van Merriënboer J, Kirschner P, Kester L. Taking the load off a learner's mind: Instructional design for complex learning. Educ Psychol 2003;38:5-13.

39. van Merriënboer J. The end of software training? J Comput Assist Lear 2000;16:366-75. 


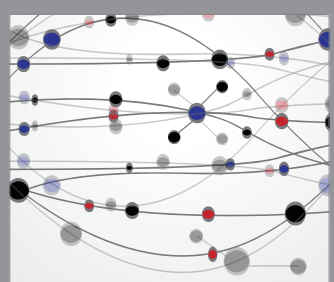

The Scientific World Journal
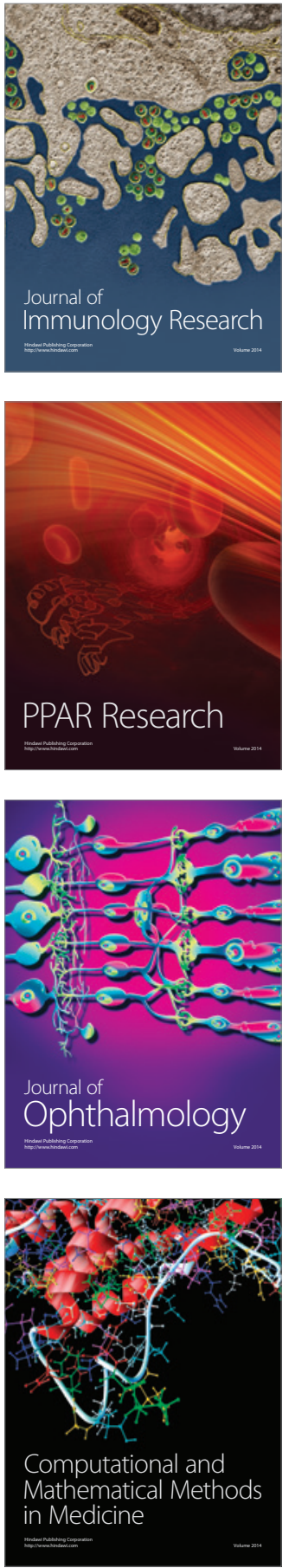

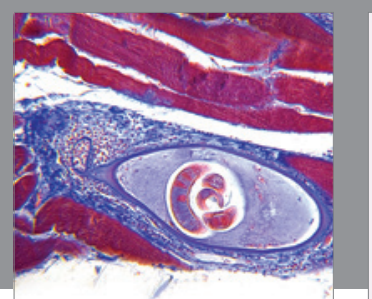

Gastroenterology Research and Practice

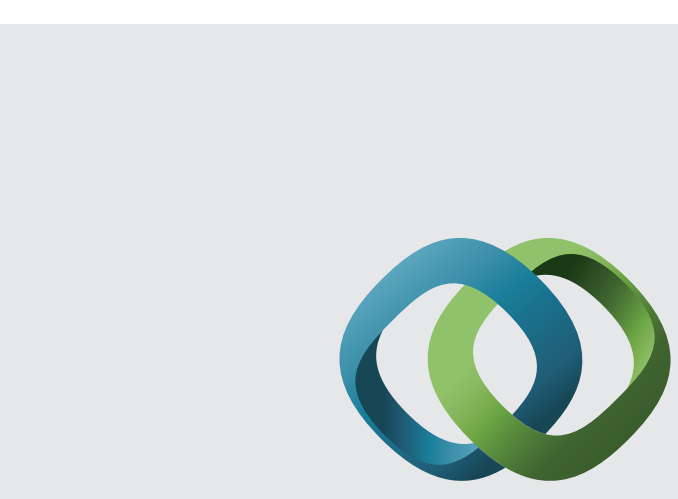

\section{Hindawi}

Submit your manuscripts at

http://www.hindawi.com
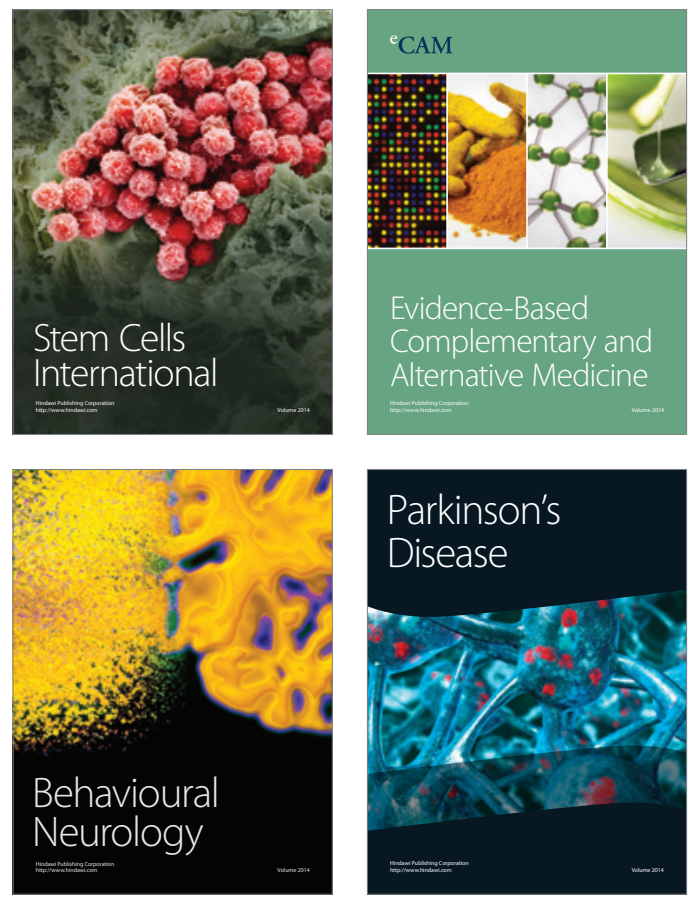
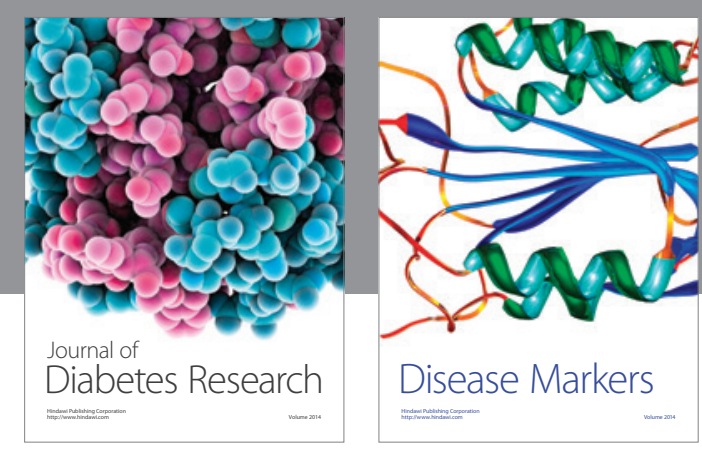

Disease Markers
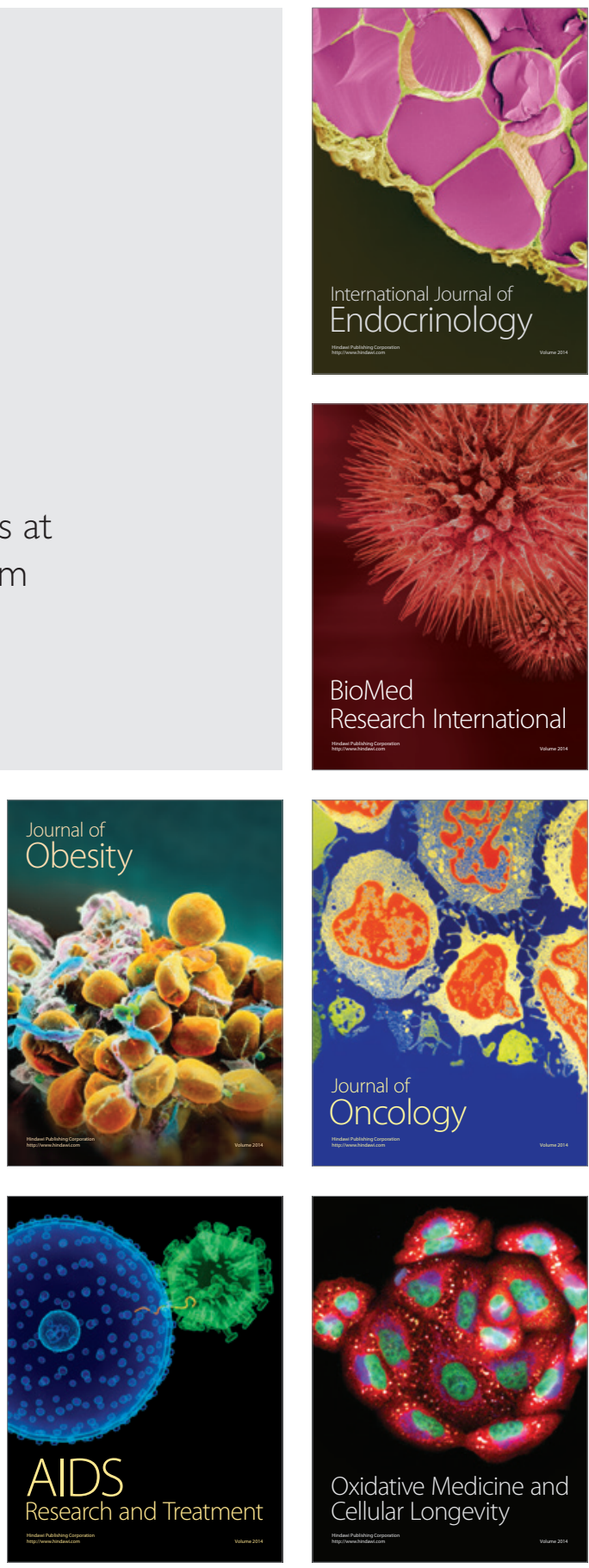